\title{
Measurement of changes in forehead height after endoscopic forehead lift
}

\author{
Jae Min Chung ${ }^{1}$, Won Ki Kang', \\ Jeong Su Shim ${ }^{2}$ \\ ${ }^{1} \mathrm{~V}$ Aesthetic Plastic Surgical Clinic, \\ Daegu; ${ }^{2}$ Department of Plastic and \\ Reconstructive Surgery, Daegu Catholic \\ University School of Medicine, Daegu, \\ Korea
}

\begin{abstract}
Background Endoscopic forehead lift effectively corrects brow ptosis, and is less invasive and has fewer complications than classic forehead lift. Therefore, endoscopic procedures are often used instead of making a coronal incision. However, very few studies have investigated changes in the height of the hairline and documented exact values regarding the extent of forehead elongation after these procedures. Therefore, we conducted this study to determine the degree to which the height of the forehead changes after endoscopic forehead lift.

Methods Patients' medical records were retrospectively analyzed and measurements of clinical photography were made to investigate changes in the height of the forehead after the procedure. Subjects were divided into an experimental group $(n=33)$ and an age-matched control group $(n=33)$ for analysis; the experimental group comprised those who underwent endoscopic forehead lift from January 2015 to March 2018, and the control group comprised those who underwent upper blepharoplasty without forehead rejuvenation from July 2009 to September 2017.

Results The changes between the preoperative and postoperative height of the forehead in the experimental group were not statistically significant (right, $P=0.163$; left, $P=0.256$; midline $P=0.545$ ). However, the changes in the height of the forehead in the control group were statistically significant on the right side $(P=0.026)$ and left side ( $P=0.028)$, but not at the midline $(P=0.244)$.

Conclusions We investigated the extent of forehead elongation that occurred in cases of endoscopic forehead lift and verified that significant forehead height changes did not occur after endoscopic forehead lift.
\end{abstract}

Keywords Forehead / Eyebrow / Lifting / Endoscopy

\section{INTRODUCTION}

Endoscopic forehead lift is a procedure used for upper face rejuvenation and to correct brow ptosis effectively. This procedure is less invasive than classic forehead lift, and complications such as a long

Received: May 31, 2020 Revised: Jul 2, 2020 Accepted: Jul 3, 2020 Correspondence: Jeong Su Shim Department of Plastic and Reconstructive Surgery, Daegu Catholic University School of Medicine, 33 Duryugongwonro 17-gil, Nam-gu, Daegu 42472, Korea

Tel: +82-53-650-4581, Fax: +82-53-650-4584, E-mail: jsshim@cu.ac.kr

Copyright @ 2020 The Korean Society for Aesthetic Plastic Surgery.

This is an Open Access article distributed under the terms of the Creative Commons Attribution Non-Commercial License (https://creativecommons.org/licenses/by-nc/4.0/) which permits unrestricted non-commercial use, distribution, and reproduction in any medium, provided the original work is properly cited. www.e-aaps.org scar on the scalp, paresthesia, and alopecia occur less frequently. Therefore, endoscopic procedures are often substituted for procedures involving a coronal incision [1]. Many studies have investigated the effects of endoscopic forehead lift in terms of eyebrow morphology, aesthetics, longevity, and complications [2-5].

Forehead lift primarily raises the eyebrows and helps to flatten the skin of the forehead and temporal region. This subsequently complements the asymmetry of both eyebrows and elongates the upper third of the face due to modifications of the muscles of facial expression in the upper facial area and hairline elevation [1]. Studies analyzing the outcomes of endoscopic forehead lift in terms of external appearance have generally focused on changes in the shape and position of the eyebrows. In contrast, studies on variations in the height of the hairline are very rare [6], and it is difficult to find exact references regarding the extent of forehead elongation after a 
procedure. Therefore, the aim of this study was to determine more specifically the degree to which the height of the forehead changes after endoscopic forehead lift.

\section{METHODS}

The medical records of patients with patients who underwent endoscopic lift using Endotine (Coapt System, Inc., Palo Alto, CA, USA) from January 2015 to March 2018 were retrospectively analyzed and measurements of clinical photography were made to investigate changes in the height of the forehead after the procedure. Thirty-three patients with standardized photographs over the course of 3 months were included in the study. Subjects were divided into an experimental group $(\mathrm{n}=33)$ and an age-matched control group $(\mathrm{n}=33)$; the experimental group comprised those who underwent endoscopic forehead lift (Figs. 1, 2), and the control group comprised those who underwent upper blepharoplasty without forehead rejuvenation from July 2009 to September 2017 (Figs. 3, 4).
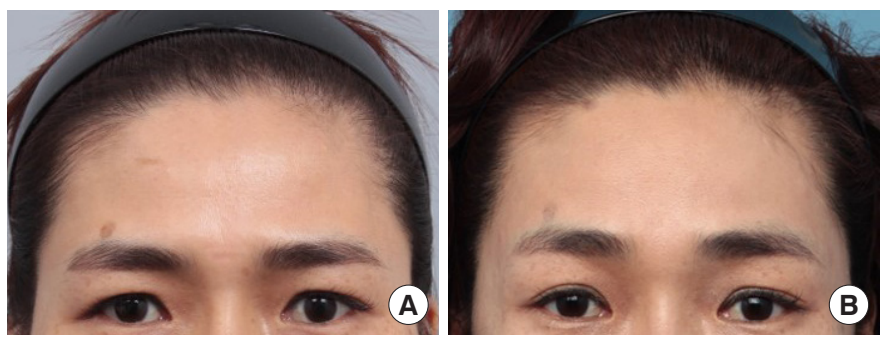

Fig. 1. Experimental group patient (female, 46 years old) who underwent endoscopic forehead lift surgery. (A) Preoperative photo, (B) postoperative photo (postoperative date: 4 months). Compared with the preoperative photograph, the right eyebrow to hairline distance was reduced from $46.2 \mathrm{~mm}$ to $43.7 \mathrm{~mm}$, the left eyebrow to hairline distance was reduced from $47.7 \mathrm{~mm}$ to $45.7 \mathrm{~mm}$, and the glabella to trichion distance was reduced from $59.7 \mathrm{~mm}$ to $57 \mathrm{~mm}$ after surgery.
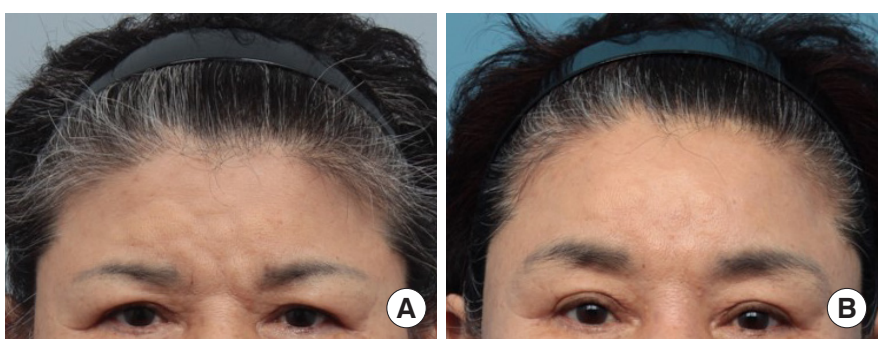

Fig. 2. Experimental group patient (female, 61 years old) who underwent endoscopic forehead lift surgery. (A) Preoperative photo, (B) postoperative photo (postoperative date: 5 months). Compared with the preoperative photograph, the right eyebrow to hairline distance increased from $38.9 \mathrm{~mm}$ to $41 \mathrm{~mm}$, the left eyebrow to hairline distance increased from $39.3 \mathrm{~mm}$ to $43.4 \mathrm{~mm}$, and the glabella to trichion distance increased from $48 \mathrm{~mm}$ to $54.6 \mathrm{~mm}$ after surgery.
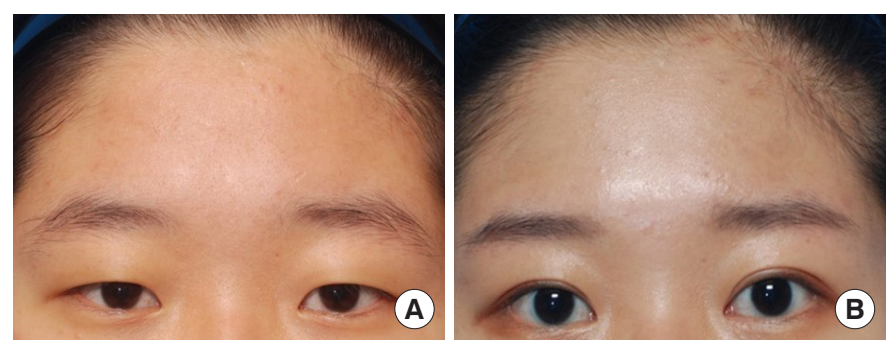

Fig. 3. Control group patient (female, 18 years old) who underwent levator advancement surgery. (A) Preoperative photo, (B) postoperative photo (postoperative date: 4 months). Compared with the preoperative photograph, the right eyebrow to hairline distance increased from $45.3 \mathrm{~mm}$ to $46 \mathrm{~mm}$, the left eyebrow to hairline distance increased from $43.9 \mathrm{~mm}$ to $44.3 \mathrm{~mm}$, and the glabella to trichion distance did not change, remaining at $53.6 \mathrm{~mm}$ after surgery.
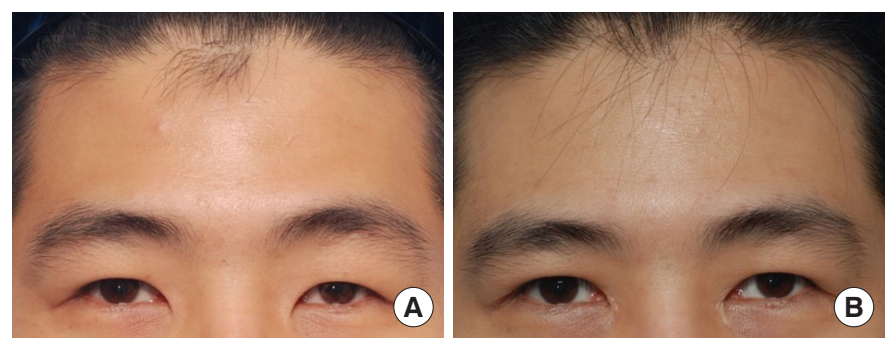

Fig. 4. Control group patient (male, 24 years old) who underwent upper blepharoplasty surgery. (A) Preoperative photo, (B) postoperative photo (postoperative date: 2 years and 4 months). Compared with the preoperative photograph, the right eyebrow to hairline distance increased from $45.3 \mathrm{~mm}$ to $48.6 \mathrm{~mm}$, the left eyebrow to hairline distance increased from $45.3 \mathrm{~mm}$ to $48.2 \mathrm{~mm}$, and the glabella to trichion distance increased from $60.8 \mathrm{~mm}$ to $63.3 \mathrm{~mm}$ after surgery.

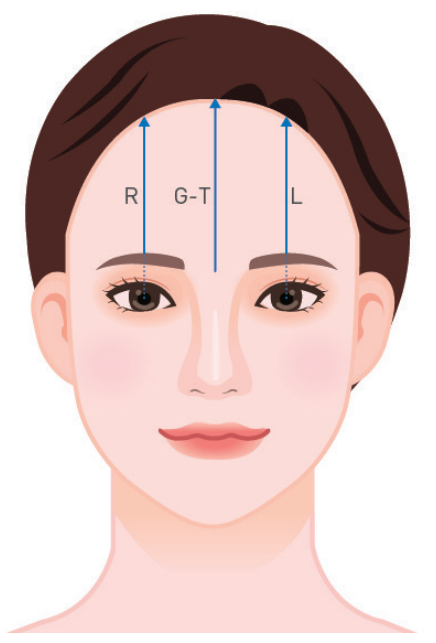

Fig. 5. The measured values of forehead height: distances from the brow, vertically connected from the center of both the pupils to the hairline, and from the brow, vertically connected from the glabella of the midline to the trichion. $\mathrm{R}$, right brow to hairline; G-T, glabella to trichion; L, left brow to hairline. 
Table 1. Experimental group: patients undergoing endoscopic forehead lift ( $\mathrm{n}=33$ )

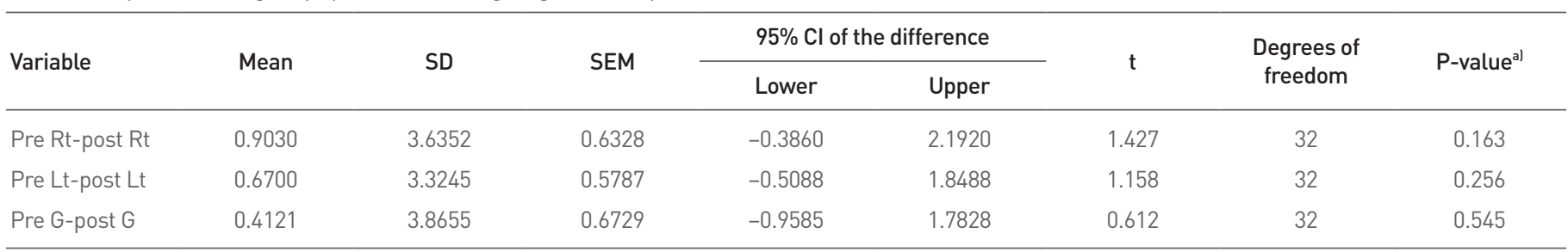

SD, standard deviation; SEM, standard error of the mean; Cl, confidence interval; pre, preoperative; post, postoperative; Rt, right; Lt, left; G, glabella to trichion. al The changes in the preoperative and postoperative height of the forehead in the experimental group were not statistically significant. $\mathrm{P}<0.05$ was considered to indicate statistical significance.

Table 2. Control group: patients undergoing upper blepharoplasty $(n=33)$

\begin{tabular}{|c|c|c|c|c|c|c|c|c|}
\hline Variable & Mean & SD & SEM & \multicolumn{2}{|c|}{$95 \% \mathrm{Cl}$ of the difference } & $\mathrm{t}$ & $\begin{array}{l}\text { Degree of } \\
\text { freedom }\end{array}$ & P-value al \\
\hline Pre Rt-post Rt & -2.3848 & 5.8778 & 1.0232 & -4.4690 & -0.3007 & -2.331 & 32 & 0.026 \\
\hline Pre Lt-post Lt & -2.3121 & 5.7620 & 1.0030 & -4.3552 & -0.2690 & -2.305 & 32 & 0.028 \\
\hline Pre G-post G & -1.3061 & 6.3193 & 1.1000 & -3.5468 & 0.9347 & 0.935 & 32 & 0.244 \\
\hline
\end{tabular}

SD, standard deviation; SEM, standard error of the mean; Cl, confidence interval; pre, preoperative; post, postoperative; Rt, right; Lt, left; G, glabella to trichion. ${ }^{a}$ The changes in the height of the forehead in the control group were statistically significant on the right side and left side, but not at the midline. $\mathrm{P}<0.05$ was considered to indicate statistical significance.

The measured values of forehead height were compared between the groups in terms of the distance from the brow, vertically connected from the center of both the pupils to the hairline, and from the glabella of the midline to the trichion (Fig. 5). Technical variations in the photos were corrected by comparing the average size of pupils. The ImageJ program was used as a tool for measuring the photos. SPSS version 18.0 (SPSS Inc., Chicago, IL, USA) was used for the statistical analysis and statistical significance was verified using the paired $t$-test. Statistical significance was considered at a P-value of $<0.05$.

\section{RESULTS}

The average age of the 33 patients who underwent endoscopic forehead lift was 41.12 years (range, 16-70 years) and the average age of the age-matched control group was 41.09 years (range, 18-75 years). The follow-up durations for preoperative and postoperative clinical photographs were 5.15 and 7.19 months, respectively.

No differences were observed in the history of medication use and other associated diseases between the groups. The changes between the preoperative and postoperative height of the forehead in the experimental group were not statistically significant (right, $\mathrm{P}=$ 0.163 ; left, $\mathrm{P}=0.256$; and midline, $\mathrm{P}=0.545$ ). In the control group, the changes in the height of the forehead were statistically significant on the right side $(\mathrm{P}=0.026)$ and the left side $(\mathrm{P}=0.028)$, but there was no significant difference at the midline $(\mathrm{P}=0.244)$ (Tables 1,2).

\section{DISCUSSION}

We referred to the study by Knize [7] for information about the anatomical structures of the upper facial area relevant when performing forehead lift. Through this study, we obtained data on the anatomical concepts underlying the surgical procedure, helping us to anticipate its effects. Regarding the method of performing endoscopic forehead lift, there have been many discussions of the region and range of detachment, as well as fixation methods. Despite these variations, the basic principle of this surgical procedure is to completely release the ligaments and soft tissues around the eyebrows, affecting the shape of the eyebrows and pulling down the soft tissues, and to securely fix them to a new position. In the early 2000s, a study showed that endoscopic forehead lift had no significant advantage over the existing method in terms of complications and effectiveness [5]. Furthermore, it is considered to be a safe procedure with fewer complications than the traditional technique, although there are some limitations in terms of its application [4]. Over the years, this technique has improved, and its advantage of being less invasive helps many patients agree to undergo surgery using this method more readily than existing open procedures. The main purpose of this surgical procedure is eyebrow repositioning, which has been investigated in many studies. Therefore, with an emphasis on the correction of brow ptosis, the current endoscopic forehead lift is more commonly referred to as endoscopic brow lift. Forehead height, forehead contour, and forehead rhytides are considered when selecting the method for forehead lift. Nahai [8] and Guyuron and Lee [9] have investigated this issue through compari- 
sons among the methods of open, coronal, pretrichial, limited, and endoscopic incision. Nahai [8] demonstrated that the endoscopic forehead lift has less of a lifting effect than other procedures; however, it has an effect on hairline elevation, results in less scarring, and leads to sensory changes. Furthermore, Guyuron and Lee [9] suggested that endoscopic forehead lift is more suitable in patients with relatively few forehead rhytides and no serious brow ptosis; Guyuron classified it as a procedure with a lower possibility of forehead elongation [9]. Due to the abovementioned issues, endoscopic forehead lift is somewhat difficult to perform in patients with a high hairline. The issue of a high hairline limiting the choice of a procedure is distinct from the issues that arise regarding forehead height after the procedure. We focused on the changes that occurred in the height of the forehead after the procedure.

The general complications of endoscopic forehead lift are bleeding, nerve injury, scarring alopecia, brow asymmetry or malposition, lagophthalmos due to brow over-elevation, and dry eye syndrome $[4,10]$. We investigated changes in the height of the forehead, which is an issue that may arise after surgery, even though it is not classified as a complication. Generally, the forehead is enlarged after a forehead lift, and forehead elongation is particularly likely to occur using the open method. Therefore, to adjust the forehead height, forehead reduction via a pretrichial incision is performed at the same time. As mentioned above, endoscopic forehead lift also has a possibility of forehead elongation, but the extent of elongation is unclear. Patients might not want forehead elongation after surgery of the brow and forehead lift. There are methods to adjust the changes in the hairline in endoscopic forehead lift [11]. However, even in studies investigating how to lower the hairline by foreheadplasty, it was difficult to determine to what extent the height of the forehead changed. Guyuron et al. [6] in 2014 studied forehead height from different perspectives in a report on hairline recession. They reported that there was less change in hairline recession with aging if an open forehead lift via the trichial incision was performed along with shortening of the forehead at the same time. That study evaluated long-term results in terms of hair loss and changes in the hairline with time and the aging process, but we could not determine how the procedure changed the forehead height. Lee [12] reported that 26 cases of endoscopic forehead lift showed forehead elongation of $5.5 \%$, but did not specify the standard used to measure the changes in height. In a study on efficacy in forehead rejuvenation, Guyuron and Lee [9] addressed forehead height disharmony as a possible problem after surgery and suggested that endoscopic foreheadplasty should be performed to minimize forehead elongation. The ideal ratio of the forehead is one-third of the upper face, and the degree of elongation of the forehead is classified as minimal ( $<5 \mathrm{~mm}$ excess), mild to moderate (5-10 $\mathrm{mm}$ excess), and severe ( $>10 \mathrm{~mm}$ excess). However, we had difficulties finding specific studies on this classification and the occurrence of the effect.

Thus, we conducted a study to investigate the degree to which forehead elongation occurred in patients who underwent endoscopic forehead lift, and found no significant changes between preoperative and postoperative measurements in the three regions (Fig. 5). However, there was a significant change in the height of the forehead on both sides in patients in the control group who underwent upper blepharoplasty without forehead rejuvenation. We have a few comments on these results. First, in endoscopic forehead lift, even if the hairline moves backward to a certain extent, the brow position is adjusted to be higher. Consequently, we can infer that the actually observed height of the forehead might not change dramatically. In endoscopic forehead lift, the most common place where brow elevation occurs is the arch area of the brow on a vertical line at the lateral margin of limbus, but the medial and lateral areas of the brow are adjusted along with the elevation. Thus, the glabella, a standard point below the midline of the forehead, will also be adjusted to be higher than its position before the operation. Therefore, it is considered that there will be no actual changes in the height of the forehead after endoscopic forehead lift.

It should be kept in mind that obtaining a higher hairline and expanding the distance from the eyebrows to the hairline have different meanings in the context of the whole face. After endoscopic forehead lift, the hairline in the whole face may become higher. In our experience, a hairline that once has been pulled up to some extent after surgery does not descend again, but it shows the progress of tissue adhesion in the forehead skin flap in the state of being pulled up. Therefore, even if the height of the forehead itself does not change dramatically, the patient may feel that the height of the forehead increases. This point will be meaningful to investigate in another study on changes in the proportions of the face. However, we analyzed patients who underwent upper blepharoplasty without forehead rejuvenation as a control group and found that they had significant changes in the height of the forehead. Therefore, it is worth noting that for upper blepharoplasty with simple skin excision, levator resection or levator plication is simultaneously performed. Doing so reduces the degree to which the position of the brow, which was elevated by the frontalis muscle, is affected by that and adjusts it to be lower after surgery, resulting in the correction of pseudoptosis or blepharoptosis. We can associate this result with the adjusted position of the brow after surgery. However, we think that we would be able to obtain more specific results if we had more data, because the number of patients in our experimental and control groups was small. The selection of the control group is another concern in our study. Instead of the method of selecting the control group used in this study, meaningful results might be achieved by using another approach, such as selecting patients who underwent direct brow lift or comparing changes in forehead height with control patients who underwent surgery using the conventional approach. Our study measured changes in height using two-dimensional photographs. It therefore cannot be concluded that this method fully reflects actual height changes. A comparative study is need- 
ed to compare the measurement results of the actual forehead height before and after surgery, which would provide more accurate results.

In conclusion, we verified that significant forehead height increases did not significantly occur after endoscopic forehead lift. These findings will help to provide patients with more comprehensive explanations regarding possible changes after the procedure, such as changes in eyebrow shape and potential changes in forehead height, during the preoperative evaluation.

\section{NOTES}

\section{Conflict of interest}

No potential conflict of interest relevant to this article was reported.

\section{Ethical approval}

This study was approved by the Institutional Review Board of Daegu Catholic University Medical Center (IRB No. CR-20-114) and performed in accordance with the principles of the Declaration of Helsinki.

\section{Patient consent}

The patients provided written informed consent for the publication and the use of their images.

\section{ORCID}

Jae Min Chung

https:// orcid.org/0000-0002-8893-5876

Won Ki Kang https://orcid.org/0000-0003-2329-4729

Jeong Su Shim

\section{REFERENCES}

1. Perenack JD. The endoscopic brow lift. Atlas Oral Maxillofac Surg Clin North Am 2016;24:165-73.

2. Jones BM, Lo SJ. The impact of endoscopic brow lift on eyebrow morphology, aesthetics, and longevity: objective and subjective measurements over a 5-year period. Plast Reconstr Surg 2013;132:226e-238e.

3. Iblher N, Manegold S, Porzelius C, et al. Morphometric long-term evaluation and comparison of brow position and shape after endoscopic forehead lift and transpalpebral browpexy. Plast Reconstr Surg 2012;130:830e-840e.

4. De Cordier BC, de la Torre JI, Al-Hakeem MS, et al. Endoscopic forehead lift: review of technique, cases, and complications. Plast Reconstr Surg 2002;110:1558-68.

5. Chiu ES, Baker DC. Endoscopic brow lift: a retrospective review of 628 consecutive cases over 5 years. Plast Reconstr Surg 2003;112:62833.

6. Guyuron B, Gatherwright J, Totonchi A, et al. Cessation of hairline recession following open forehead rejuvenation. Plast Reconstr Surg 2014; 133:1e-6e.

7. Knize DM. Anatomic concepts for brow lift procedures. Plast Reconstr Surg 2009;124:2118-26.

8. Nahai FR. The varied options in brow lifting. Clin Plast Surg 2013;40: 101-4.

9. Guyuron B, Lee M. A reappraisal of surgical techniques and efficacy in forehead rejuvenation. Plast Reconstr Surg 2014;134:426-35.

10. Lighthall JG, Wang TD. Complications of forehead lift. Facial Plast Surg Clin North Am 2013;21:619-24.

11. Hamas RS, Rohrich RJ. Preventing hairline elevation in endoscopic browlifts. Plast Reconstr Surg 1997;99:1018-22.

12. Lee HK. Endoscopic forehead lift using endotine(R). J Korean Soc Aesthetic Plast Surg 2007;13:9-17. 